\title{
VR Neuro Game: a Virtual Reality Game to Support Neuroanatomy Teaching and Learning
}

\author{
Vinícius Souza (1) [ Universidade do Vale do Rio dos Sinos | viniciuscs@unisinos.br ] \\ Anderson Maciel (1) [ Universidade Federal do Rio Grande do Sul | amaciel@inf.ufrgs.br ] \\ Luciana Nedel (1) [ Universidade Federal do Rio Grande do Sul |nedel@inf.ufrgs.br ] \\ Regis Kopper (1) [ University of North Carolina at Greensboro $\mid$ kopper@uncg.edu ] \\ Klaus Loges (10) [ Universidade do Vale do Rio dos Sinos|kloges@unisinos.br ] \\ Eliane Schlemmer (D) [ Universidade do Vale do Rio dos Sinos | elianes@unisinos.br ]
}

\begin{abstract}
Using virtual environments (VEs) is a safer and cost-effective alternative to training people in different contexts. Immersive Virtual Reality (VR), combined with game aspects, have the potential to improve the user experience in the VE by increasing realism, engagement, and motivation. In education, there is a consensus about its contribution in the teaching and learning processes. However, in Brazil, only a few research groups have developed projects that involve the development of VR for education, due to technical difficulties and high costs. This manuscript presents the development and evaluation of an VR serious game to support the learning of neuroanatomy, an extended version of our previously published paper at the SVR $2020^{1}$. In this version, we present the results of four different user studies, involving 57 participants, which suggest that the VR Neuro Game is easy to use, even by inexperienced subjects in VR, and is potentially useful for teaching and learning processes, both by individual students and groups of students and also in remote learning. In addition, the game was considered fun and did not cause discomfort. When comparing the knowledge test performance before and immediately after the experiments, we found significant difference only for the virtual condition. The same could be observed for retention results.
\end{abstract}

Keywords: Virtual Reality, Presence, User Evaluation

\section{Introduction}

The digital transformation that was already underway in all society was radically accelerated by the social isolation imposed by the Covid-19 pandemic Cerf (2020). The nowadays challenges forces all professionals to possess a range of collaborative, interdisciplinary, and technology skills Wiberg et al. (2020). In the educational area, institutions need to implement digitization strategies that will foster a range of alternatives to the traditional presential classes, enabling students to keep learning and to use the technology critically and creatively Cerf (2020); Ananiadou and Claro (2009). Equipping education professionals and students with technology tools and digital competencies is essential to prepare them for the inevitable shift caused by digital transformation, radically accelerated by the Covid-19, that influences every part of societal and professional life Oliver and de St Jorre (2018); Bond et al. (2018).

Virtual Reality (VR) has been widely used to knowledge transfer in domains as diverse as health Kruglikova et al. (2009); Silverstein et al. (2002) and manufacturing MurciaLópez and Steed (2018); Jou and Wang (2013). Moreover, more recently, some games are constructed over pedagogical and educational criteria to reach its serious purpose, the so called serious games. However, there are still few researches investigating the potentialities and limitations of VR games, especially regarding newly launched devices that provide unconventional interaction experiences Nedel et al. (2016). The applications of VR in education are many and there is a consensus of its benefits in the teaching and learning processes. Among the possible benefits are the possibility of expanding the perceptions of the five senses, representing more than the real state of affairs, greater engagement with the student, appropriation according to each person's rhythm, exploration instead of deduction, active learning, interacting and facilitating a global analysis and their interrelationships. The cognitive process is not just about problem solving, but it also has inventiveness and creation. The data processing perspective no longer fits as the only answer to cognition. Objective and subjective are supporting the production of cognition. The available technology and cost limitations will define the type of application to be developed in each case.

Indeed, the application of VR in education is a great leap for teaching methods after the multimedia, computers, and the Internet. The most commonly used formats of such virtual teaching environment include virtual technical skill training, virtual laboratory, virtual instructions, virtual campus, and virtual distance learning Jou and Wang (2013).

In the Covid-19 context, for instance, a remote, scalable, efficient, and high-quality education is strongly necessary to guarantee the continuity of the teaching and learning process, and VR is seen as a promising and effective tool to the different education areas, including the health education Cerf (2020); Crisp et al. (2008).

A recent literature review that investigated the effectiveness of VR for health professionals' education Kyaw et al. (2019a) has found that when compared with traditional education or other types of digital education, VR may improve post-intervention knowledge and skills. Virtual environments could, in fact, deliver cost-efficient, safe and potentially effective training. However, the majority of the studies assess the effectiveness of non-immersive VR or individual- 
use immersive VR, and there is a need to explore more on the effects of VR with different levels of immersion and collaboration.

Panchaphongsaphak, Burgkart and Riener Panchaphongsaphak et al. (2005) affirmed that "the brain is known as the most complex organ in the human body. Due to its complexity, learning and understanding the anatomy and functions of the cerebral cortex without effective learning assistance is rather difficult for medical novices and students in health and biological sciences."

In such context, this manuscript presents the development of a VR serious game and the evaluation of how it supports neuroanatomy teaching and learning processes in health undergraduate education. For the system evaluation, four user experiments were conducted with the aim to investigate the knowledge transfer and retention in individual and grouplearning fashion, including participants with different immersion levels, as so in remote use.

In the remainder of the paper, Section 2 presents the background and the previous projects related to this work. Section 3 presents the design of the neuroanatomy VR game, while Section 4 describes the four user experiments conducted. Finally, conclusions are presented in Section 5.

\section{Background and Related Work}

Digital education is the process of teaching and learning by means of digital technologies and contemplate a multitude of educational approaches, concepts, methods, and technologies. It can include, but is not limited to, computer-based education, massive open online courses, virtual reality (VR), patient simulation mannequins, mobile learning, serious gaming, and psychomotor skills trainers Car et al. (2019). Nevertheless, the use of educational technologies depends on the needs of the process involved and the available resources, and its usage is not a decisive factor in the acquisition of knowledge Muller Queiroz et al. (2019).

According to Billinghurst and Duenser Billinghurst and Duenser (2012), immersive VR can be stimulating in the learning process, either by repetition or by more complex cognitive processes. The possibility of experiencing interactive situations during the immersion stimulates the individual's senses in learning, whether in a recreational or serious game. In this situation, the individual has the possibility of moving from the theory and have an experience. Immersion gives the player the opportunity to experience emotions and engagement that are typical of VR. Besides, Papert Papert (1993) proposes constructionism as a form of learning in which subjects are autonomous agents in the construction of their knowledge through experimentation and construction in problem solving. Based on this, there is the possibility of building knowledge and learning through interaction, cooperation and meaning, individually and in groups, promoting creativity, experimentation and reflection Muller Queiroz et al. (2019).

According to Maturana and Varela's autopoiesis theory Maturana and Varela (1987), when the player comes into contact with VR, the relationships they will have will emerge from the relationship with the environment in question and, from this, the process of learning and cognition. These relationships will occur according to the emotions that will arise and your previous and acquired experiences during the game. Contextualization will be a crucial point of the knowledge development process through the couplings made possible by the individual-environment interaction Maturana (1990), whether in an immersive environment or not. Couplings occur through the interaction of the environment with the individual in which the representation is given in the context in which the observer/player creates its meaning, then generating its knowledge Dias and Kastrup (2013).

Slater Slater (2014) already affirmed in 2014 that VR had become a commonplace tool in many fields of science, such as technology, education, psychological therapy, medical rehabilitation, marketing, entertainment, and industry, and was surely about to become commonplace in homes. Furthermore, SlaterSlater et al. (1995); Slater and Steed (2000); Slater (2004) affirms that presence is an important feature of VR systems related to the users' sense of being present in the virtual environment. Thus, many researchers and studies argue that the greater the sense of presence, the greater the chances that the users' behavior in the VR will be similar to their behavior if the situation was real, and, consequently, the greater the effectiveness of the use of VR for the training, therapy or entertainment Slater et al. (1995); Sjölie (2013); Schuemie et al. (2001).

On the other hand, the gaming world went from pixelated 2D to high-definition 3D in just a decade Donovan (2010). Just like ordinary video games, serious games consist of gameplay, challenge, interaction, and objective, while "gamified" applications merely incorporate elements of games. Learning games are constructed over pedagogical and educational frameworks, which define the relationship between learning and gaming mechanisms, ensuring a successful combination of such factors to reach its serious purpose Michael and Chen (2005); Yusoff et al. (2009); Menin et al. (2018).

In the health field, VR has been used in the simulation of surgeries, mainly for operative training of videolaparoscopic surgery, in the preoperative planning and in the intraoperative support, aimed at training of thus improving practical skills not easily obtained in real conditions Panchaphongsaphak et al. (2005); Hvolbek et al. (2019); KenResearch (2018). The images of virtual digital models have the advantage of allows the evaluation of the organs threedimensionally, the observation of the internal structure of the organ, the evaluation of the relations between the organs with their topographies and the production of selective visions of the body. In addition, there is no time limitation for usage Zhang et al. (2018). A recent review investigated the effectiveness of VR for health education and the results showed that, when compared with traditional education or other types of digital education, VR may improve knowledge transfer and deliver cost-efficient, safe and potentially effective training Kyaw et al. (2019a).

Three-dimensional computer graphics are increasingly used to support teaching, and different VR games have been developed and compared to traditional methods of education. Students are often more strongly motivated by VR. Immersion, presence and spatial knowledge presentation are all factors that can have a positive effect on learning Kyaw et al. 
(2019b); Samadbeik et al. (2018). In this section, we examine the previous articles on immersive VR applied for teaching, especially to educate health professionals.

Chittaro and Buttussi Chittaro and Buttussi (2015) proposed, in 2015, a VR game for educating passengers about aviation safety. They compared the proposed approach to a traditional aviation safety education method (the safety card). They assessed not only immediate learning, but extended attention to knowledge retention. A knowledge test administered before, immediately after and one week after the exposition showed that the immersive serious game was superior to the safety card in knowledge retention. The typical engagement of VR can contributes to explain the obtained superior retention. We used this study as baseline to define the protocol of our own experiment.

According to Kockro et al. Kockro et al. (2015), threedimensional (3D) computer graphics are increasingly used to support the teaching of anatomy. Thus, they proposed the Dextrobeam VR environment, which allows the presentation of spatial neuroanatomy models to larger groups of students through a stereoscopic projection system. They conducted a study where students received an audio lecture accompanied by either a PowerPoint presentation or a 3D animated tour of the same content. Students completed an exam based on the content learned and a subjective evaluation of the teaching method immediately after the lecture. Results showed that students in the 3D group achieved scores statistically noninferior to those of the 2D group, and students rated the 3D method superior to 2D teaching in four domains: spatial understanding, application in future anatomy classes, effectiveness, and enjoyableness. The authors concluded that stereoscopy enhanced 3D lectures are valid methods of conveying neuroanatomical knowledge and are well received by students. However, they suggest more research is required to define and develop the role of large-group VR systems in modern neuroanatomy curricula.

Stepan et al. Stepan et al. (2017) conducted a study with the purpose of evaluating the effectiveness, satisfaction, and motivation associated with immersive VR simulation in neuroanatomy teaching. Neuroanatomical structures were studied using either online textbooks or VR. Later, they evaluate the students' anatomy knowledge, educational experience, and motivation. No significant difference was observed in anatomy knowledge between the two groups on preintervention, postintervention, or retention quizzes. The VR group found the learning experience to be significantly more engaging, enjoyable, and useful and scored significantly higher on the motivation assessment.

Oberdörfer et al. Oberdörfer and Latoschik (2016) developed a virtual gamified training environment. Learners apply the knowledge while receiving immediate and highly immersive visual feedback about the outcomes of their inputs. Besides, by providing a flow-inducing gameplay, users are strongly motivated to practice their knowledge by experiencing a higher learning quality. According to the authors, immersion, presence and spatial knowledge presentation can have a positive effect on the training.

Kyaw et al. Kyaw et al. (2019b), conducted a systematic review to evaluate the effectiveness of VR to educate health professionals. The aim of this review was to evaluate the ef- fectiveness of VR to the educational process of health professionals and the improvement of their knowledge, cognitive skills, attitudes, and satisfaction. A meta-analysis found that VR slightly improves knowledge scores and health professionals' cognitive skills when compared with traditional learning. Overall, the certainty of evidence according to the criteria ranged from low to moderate. Authors recommended that future research should evaluate the effectiveness of immersive and interactive forms of VR.

In another review, conducted by Samadbeik et al. Samadbeik et al. (2018), the applications of virtual reality technology for training the medical groups were surveyed. The study identified that using virtual reality has improved learning in $74 \%$ of the studies, and a higher accuracy in medical practice by people trained through VR has been reported in $87 \%$ of the studies. The general results indicated that the application of virtual reality capabilities plays an important role in improving the performance of different health professionals.

Overall, the related studies showed that immersive serious games are a promising tool for health education. When compared to the traditional learning methods, they are preferred by users and promote equal or better performance, never worse. However, such effects greatly vary with the nature of the task, style of virtual environment, and the VR system setup. These motivating previous experiences and results led us to develop a VR serious game to support neuroanatomy teaching and learning, and inspired us to investigate the potential use of interactive VR systems in health education.

Moreover, collaborative learning has also been shown to help apprentices to retain the learned information longer. Thus, our study aims to advance research on the knowledge transfer and retention in immersive group-based serious game.

\section{The VR Game}

The VR game presented in this manuscript were designed by an interdisciplinary team, including computer science and education researchers, as so neuroanatomy professors. The team option was to develop a serious game, constructed over pedagogical and educational criteria to reach its serious purpose. According Melin Menin et al. (2018), a serious game consists of gameplay, challenge, interaction, and objective. In the design of our game, we chose the puzzle paradigm to emphasize a simple gameplay. This game genre can test different player skills, such as logic, strategy, pattern recognition, sequencing, and part-whole relationships Rachevsky et al. (2018).

The virtual environment is inspired in a typical neuroanatomy class scenario, where the different anatomic parts of the encephalon are presented to the students. They have the task of recognizing parts, learning their names, functions and relations. In the following, we present the game narrative in detail and the possible player actions.

The game begins showing the human virtual encephalon anatomic parts (frontal lobe, parietal lobe, occipital lobe, temporal lobe, cerebellum, corpus callosum and brainstem, and diencephalon), which are randomly arranged and colored, on a virtual table (Fig. 1). The name of each anatomical part of 


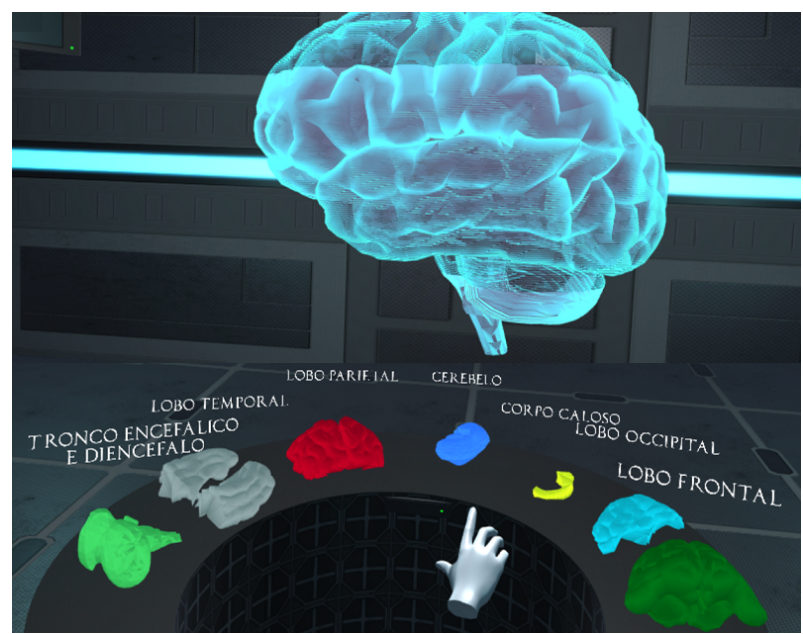

Figure 1. Screenshot of the game, which illustrates the parts of the human brain to be assembled, with the name of each part, and the reference brain.

the brain is fixed in its $3 \mathrm{D}$ model and moves in the virtual environment together with the model. The challenge is to assemble the virtual encephalon in the shortest time by manipulating the parts bimanually. As a reference, a complete encephalon, which can be rotated in 360 degrees by the users, is showed. To increase the level of difficulty, it is possible to disable the name labels.

The randomness of the position and the colors of the parts aim to maintain the challenge between matches, minimizing the possibility of solution by mere memorization. In addition, when starting a match, the user is invited to inform their name/nickname, considering that the game presents the 10 shortest times ranking, as a motivational strategy for the challenge.

Using the Oculus Touch controller to mimic the hands in the virtual environment, the player picks up an anatomical part of the brain in each hand. For this, it is necessary to touch the 3D model with the virtual hand, press and hold the button that is in contact with the middle finger. Releasing this button, the virtual hand opens and the brain part is released/dropped. With one part of the brain in each virtual hand, the player will be able to rotate and translate the parts using natural hand movements while looking for the correct pose to fit them. When two parts are put together in the correct position, a magnetic action fix them and they remain connected forming a new part. This assembled new part has to be fitted with another one, in succession, until the whole brain is assembled. At any time, the user can move the analog stick to rotate the reference brain (Fig. 2).

The didactic objective of this serious game is to support the learning of names, positions, function and relations of the different human encephalon anatomy parts. It will be assessed on a group-based learning context, where it is introduced as a playful, active and innovative method.

The game was developed in Unity3D and for evaluation a Dell XPS 8900 computer with $3.6 \mathrm{GHz}$ Intel(R) Core i77700 processor, 16GB RAM and NVIDIA Gforce GTX 1060 $6 \mathrm{~GB}$ graphics card was used. The VR devices used were the Oculus Rift CV1 and the Oculus Touch control.

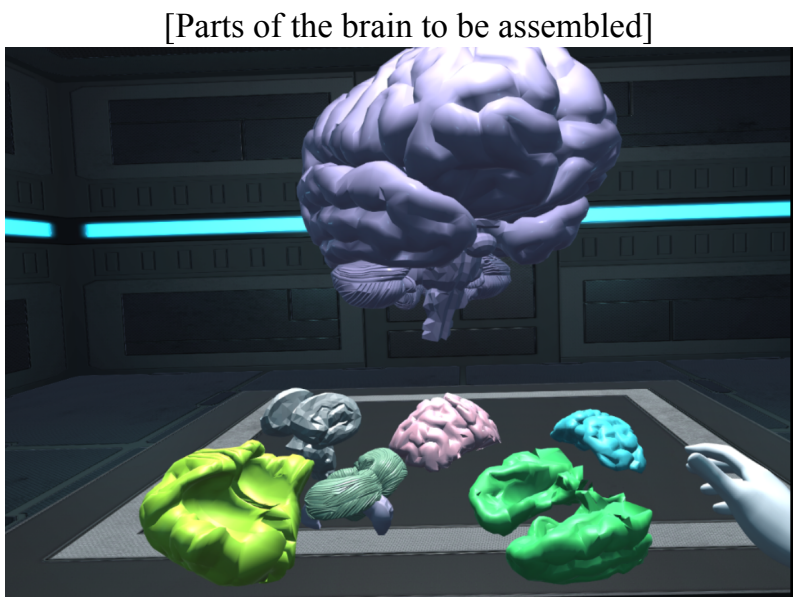

[Partial assembly of the brain]

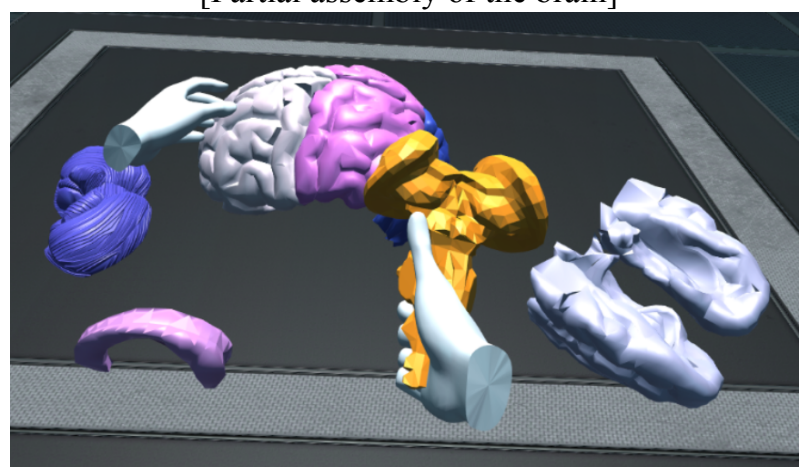

[Completed human encephalon]

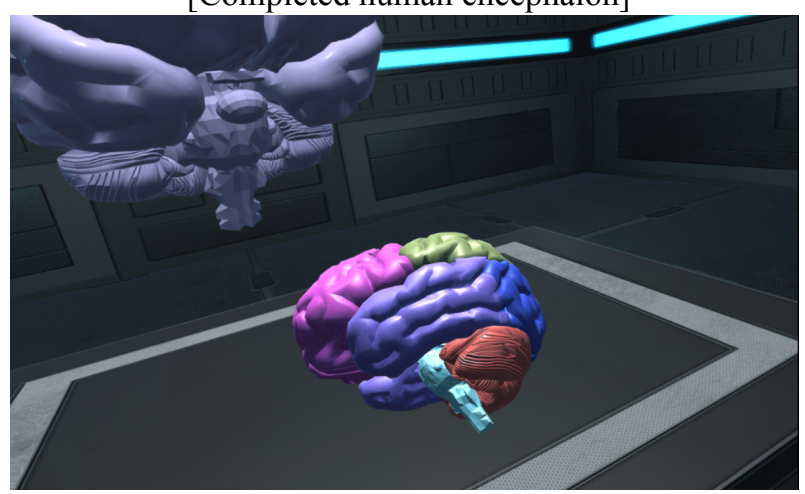

Figure 2. Stages of the virtual game, being that the game started with the main parts of the brain randomly distributed on a virtual table. The game objective is to assemble the brain based on its $3 \mathrm{D}$ anatomic parts, in the shortest time.

\section{User Evaluation}

The primary goal of the user evaluation was to determine whether or not the VR Game is a suitable platform to support the neuroanatomy teaching and learning processes. Consequently, four user experiments were conducted to investigate the knowledge transfer and retention in individual and group-learning fashion, including participants with different immersion levels, as so in remote use.

\subsection{First User Evaluation: Preliminary}

This section briefly presents the VR Neuro Game preliminary user evaluation Souza et al. (2018). 


\subsubsection{Participants}

In order to carry out a preliminary user evaluation, the game was used by 10 students, 5 men and 5 women (age $M=21.8$ $\mathrm{SD}=4.8$ ), from health and education undergraduate. The evaluation aimed to identify limitations and potentialities as well as to obtain suggestions for improvement.

\subsubsection{Procedure}

The procedure followed a typical protocol, beginning with a general explanation, followed by the signature of the consent term and of use image term. Subsequently, a questionnaire was applied to characterize the participants and, shortly thereafter, the VR head-mounted display (HMD) and controls were adjusted in the participant. After completing the game, each subject answered a questionnaire, with open and closed questions, to evaluate the experience. Through a 5point Likert scale, participants opined about the ease of use, fun, utility and possible discomfort caused by VR. In a 7 point scale they answered 6 questions from the SUS presence questionnaire Usoh et al. (2000). Additionally, the subjects recorded their perceptions about the potentials and limitations of the game in open-ended questions. All matches were recorded for later analysis (Figure 3).

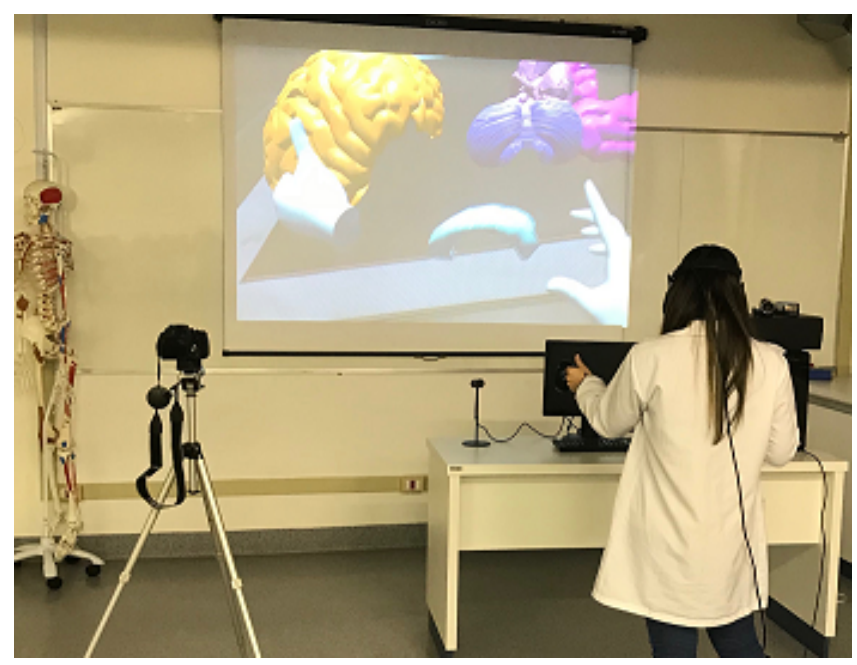

Figure 3. Student playing the VR neuroanatomy game.

\subsubsection{Results and Discussion}

As can be seen in Figure 4, the game was considered easy to use $(M=4.0)$, even though most participants have no previous VR experience, and potentially helpful for neuroanatomy teaching and learning process $(M=4.3)$. In addition, the game was considered fun $(\mathrm{M}=4.7)$ and did not cause discomfort $(\mathrm{M}=1.9)$, commonly known as cybersickness in VR. Ease of use is probably associated to the intuitive and natural way of picking up and dropping the parts, provided by the use of Oculus Touch controls, which control virtual hands. The fun is possibly associated to the immersive experience provided by Oculus Rift and by the game based learning.

Considering the results of the SUS presence questionnaire, a high average (5.8) was obtained, and for six questions averages above 6.1 were obtained. The SUS scale ranges from

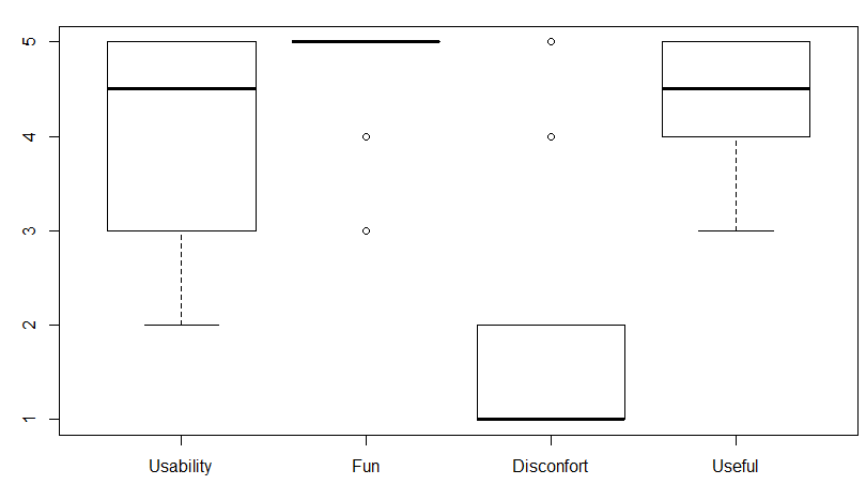

Figure 4. Box plot for the usability, fun, discomfort, and useful. The thick black lines are the medians and the boxes represent the interquartile ranges (IQR).

1 to 7 , with 7 for the sensation of being in a real given place Usoh et al. (2000).

Regarding to the game potentialities, it is possible to emphasize that the participants affirmed that the game can aid in the neuroanatomy learning on a different form, motivating and easier understanding. When questioned about how they felt during the game, subjects reported that they felt as if they were actually in another setting, such as in a real practice class. As for the limitations, there were some comments related to the pieces fitting difficulty, to the impossibility to undock the pieces already in place and to the imprecision of the virtual hands.

In the open question, the following comments were stand out: "I felt very comfortable during the game, learning this way stimulated me to want to know more" and "I think it will be very good for students who have no idea what these pieces are, it is easier to understand".

\subsection{Second User Evaluation: Individual Learning}

This section presents a formal within-subjects experiment performed to verify the hypotheses defined Souza et al. (2019).

\subsubsection{Hypothesis}

The general hypothesis defined in this study is that the neuroanatomy learning process based on the use of a virtual encephalon has similar results to the present method, based on a synthetic encephalon. This general hypothesis was detailed in 5 specific hypotheses, presented below.

- H1: The use of virtual encephalon produces similar results to the use of synthetic encephalon in neuroanatomy learning.

- H2: The difficulty of virtual encephalon assembly is similar to the synthetic encephalon assembly.

- H3: The sense of presence in the virtual encephalon assembly is smaller than in the synthetic encephalon assembly does.

- H4: The virtual encephalon assembly causes more discomfort than the synthetic encephalon assembly.

- H5: The fun in the virtual encephalon assembly is bigger than in the synthetic encephalon assembly. 


\subsubsection{Dependent and independent variables}

The aim of this study was to evaluate the presence and learning between the different test conditions, that is, the assembly, performed individually by the participants, of the human encephalon with synthetic and virtual parts (Fig. 6 and 7). The independent variable was the type of encephalon to be assembled (synthetic and virtual) and the dependent variables were the presence and learning (grade in the knowledge test).

\subsubsection{Participants}

In order to carry out a user evaluation, the serious game was used by 16 students, 13 women and three men, from different undergraduate courses and stages, without motor limitations $^{2}$. Some students from courses not related to the health area participated in the sample, with the aim of also including participants without prior neuroanatomy knowledge. The participants' age range was 17 to 40 years, with a mean age of 26.8 years and a standard deviation of 6.3. Concerning the course, 7 were from Psychology, 4 from Physiotherapy, 2 from Law, 1 from Biology, 1 from History and 1 from Publicity. About the course stage, 3 are in the first year, 3 in the second year, 3 in the third year, 4 in the fourth and 3 in the last year.

When asked about their neuroanatomy knowledge, the participants answered a 4 point Likert scale (none, little, medium, high). Four subjects said they were unaware, six declared to have little knowledge and six average knowledge. Participants were also asked to indicate, on a scale from 0 to 100 , their degree of knowledge concerning the anatomy of the human encephalon, being the mean 28.44 and the standard deviation 20.47. Related to the knowledge test, developed by a neuroanatomy professor, the mean performance was 20.38 , with a standard deviation of 20.85 .

With respect to the VR experience, participants responded to a numerical scale (none, once, between 2 and 5 times, between 6 and 10 times and more than 10 times), so that 7 subjects never used, 5 used once, 2 used between 2 and 5 times and 2 used between 6 and 10 times. As for the 3D video gaming experience, participants also responded to a numerical scale (never, once a month, once a week, once a day, more than once a day): 9 subjects never play, 5 play once a month and 2 play once a week.

\subsubsection{Metrics}

Objective measures (performance and time), subjective (presence, ease of assembly, discomfort and fun in assembling and usefulness for neuroanatomy learning) were used in this study. The performance was obtained in the knowledge test, the time by the game log and the subjective measures were collected through the application of questionnaires.

The knowledge test, developed by the professor responsible for the class of neuroanatomy in the university, was composed of an image of the human brain (Fig. 5), in which were indicated the 6 parts that compose it. The participant

\footnotetext{
${ }^{2}$ Limitations of functioning in the osseo-articular, muscular and / or nervous system.
}

was asked to indicate the name of each of the parts, according to the image indication, and the result was attributed in a score from zero to 100 points.

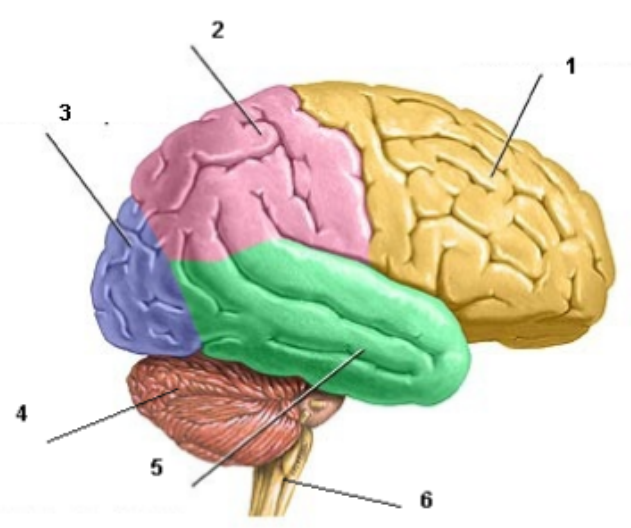

Figure 5. Human encephalon image used in the knowledge test.

The virtual encephalon assembly time in the virtual has been recorded in a text file generated by Unity at the end of each section of the game. In the synthetic encephalon assembly, the time was counted and recorded by the researcher.

To measure presence, the Slater-Usoh-Steed questionnaire Slater et al. (1994), also known as SUS, was used. The SUS questionnaire underwent some changes and currently consists of six items evaluated on a seven-point rating scale, 7 being the real sensation of being in a different place.

With respect to the ease of assembly, participants responded, in a 5-point Likert scale, to the affirmative sentence "It was easy to assemble the encephalon" with the following options: totally disagree, disagree, neutral, agree and totally agree.

With respect to the fun, participants also responded to a 5point Likert scale related to the affirmative sentence "It was fun to assemble the encephalon", with the following options: totally disagree, disagree, neutral, agree and totally agree.

Virtual reality sickness occurs when exposure to a virtual environment causes symptoms that are similar to motion sickness symptoms. The most common symptoms are general discomfort, headache, stomach awareness, nausea, vomiting, pallor, sweating, fatigue, drowsiness, disorientation, and apathy. To verify a possible cybersickness, a simple affirmative sentence was presented to the participants: "Assembling the encephalon caused me discomfort." Subjects also responded to a 5-point Likert scale with the same following options: totally disagree, disagree, neutral, agree and totally agree.

To verify the usefulness to the neuroanatomy learning, in the subjective participants opinion, the affirmative sentence presented was "The assembly of the human encephalon was useful for my neuroanatomy learning". Subjects also responded to a 5-point Likert scale with the same following options: totally disagree, disagree, neutral, agree and totally agree.

\subsubsection{Procedure}

The procedure followed a typical protocol, beginning with a general explanation of the experiment, signature of the con- 
sent term and use image term, characterization of the participant and application of a preliminary neuroanatomy's test of knowledge, prepared by the responsible professor at the university. Subsequently, the participant performs the assembly of the synthetic (Fig. 6) and virtual (Fig. 7) encephalon, varying the order among the participants. After each test condition, the subject answered a questionnaire, with open and closed questions, to evaluate the experience. Through a 5point Likert scale, participants opined about the ease of usage, fun, utility and possible discomfort caused by the VR. In a 7-point scale, they answered 6 questions from the SUS presence questionnaire Slater et al. (1994). Additionally, the subjects recorded their perceptions about the potentials and limitations of the game in open-ended questions and redid the knowledge test. Finally, comparative issues between the virtual and synthetic experiments were applied.

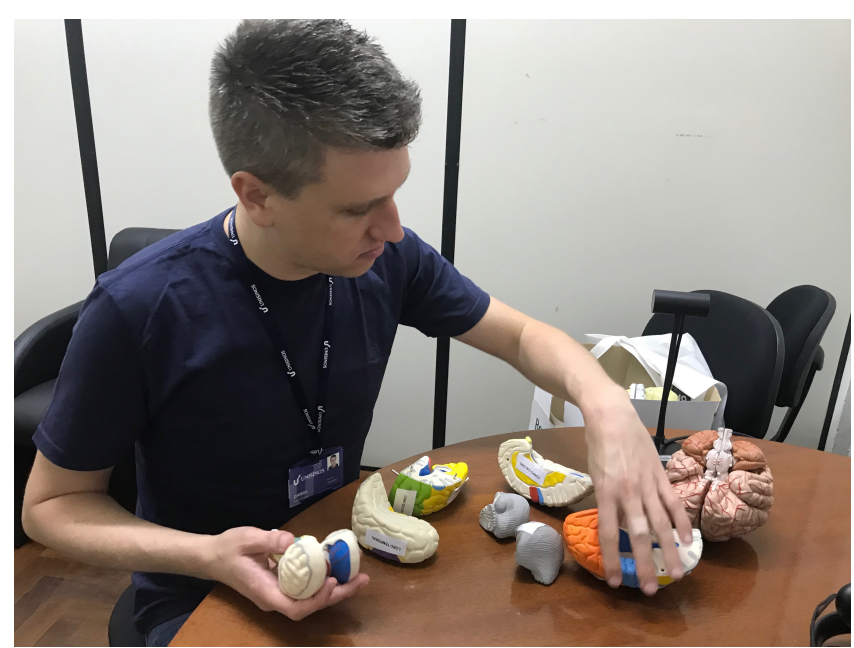

Figure 6. Individual assembly of synthetic human encephalon.

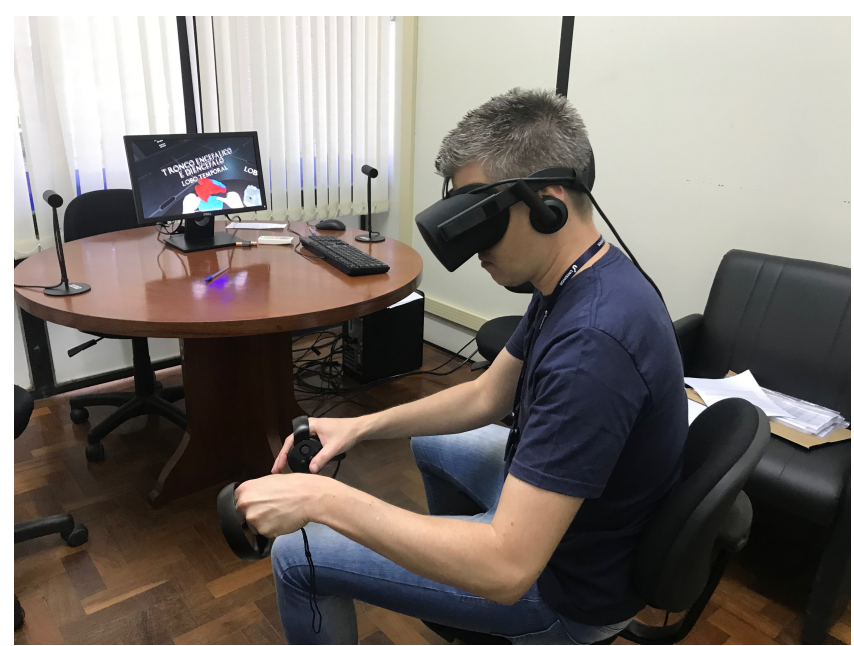

Figure 7. Individual assembly of virtual human encephalon.

\subsubsection{Results and Discussion}

For each of the aspects covered in the experiment, the Shapiro-Wilk test was applied to verify whether or not they had normal distribution, followed by an analysis of variance and paired tests, in cases in which a difference between the experimental conditions was identified, to verify among which conditions there was a significant difference. In the case of data with normal distribution, the One-way ANOVA variance test was applied and, when the difference was identified, the Student's t test was used to verify between which conditions there was a significant difference. On the other hand, for the non-normal distributed data, the non-parametric tests were applied: the Friedman test for analysis of variance and the Wilcoxon test to verify between which conditions there was a significant difference.

As described before, in the condition 1 (C1), the participant used the HMD and touch controls to assemble the virtual encephalon. In the condition 2 and (C2), the participants assembled the synthetic encephalon, that is, the present method used in the neuroanatomy course.

In the knowledge test, as showed in Fig. 8, we found a significant difference (kruskal $\mathrm{p}=0.1664$ - synthetic and $\mathrm{p}=0.4177$ - virtual) between the performance before $(\mathrm{M}=20.38 \mathrm{SD}=20.85)$ and after the experiment $(\mathrm{C} 1 \mathrm{M}=46.3$ $\mathrm{SD}=32.4$ and $\mathrm{C} 2 \mathrm{M}=47.1 \mathrm{SD}=38.4$ ), what indicates that the methods really contribute to the learning process. However, no difference was found between the experimental conditions, evidencing that the virtual condition is equivalent to the synthetic.

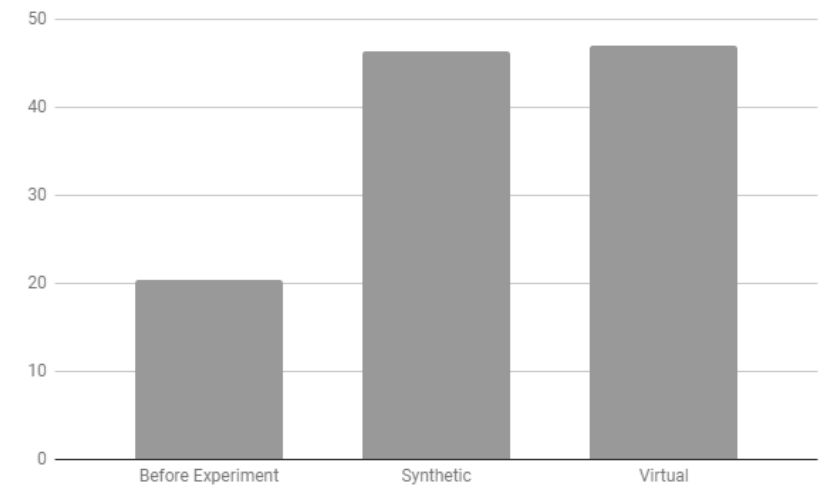

Figure 8. Knowledge test mean result, before and after each experimental condition.

Concerning the time to assemble the encephalon in the experimental conditions, in the synthetic condition the mean time was 6.14 with standard deviation of 0.13 , and, in the virtual condition, the mean time was 9.52 with standard deviation of 0.32 . It was possible to notice that the average time was higher in the virtual condition, which is acceptable since most participants are inexperienced in virtual reality. However, it is also noted that the difference in mean assembly time between conditions was very small.

The SUS questionnaire, which is composed of six items evaluated in a seven-point evaluation scale, was applied to verify to what extent the developed virtual environment allows a good level of presence in the users, so that this is an important characteristic of an AV that proposes to contribute to the learning process. As can be seen in the Figs. 9 and 10 , no significant differences were found between the test conditions (wilcoxon $\mathrm{p}=0.3049$ ), and it was expected that in the synthetic condition the averages would all be very close to 7 . This result may be associated with an inadequate interpretation of the real meaning of the sense of presence by participants, especially in the synthetic condition. However, even if 
we consider that in the synthetic condition the sense of presence is 7 in all the questions, it fair to notice that the sense of presence in the virtual condition was quite high, having a mean of 6.13 and standard deviation 0.83 .

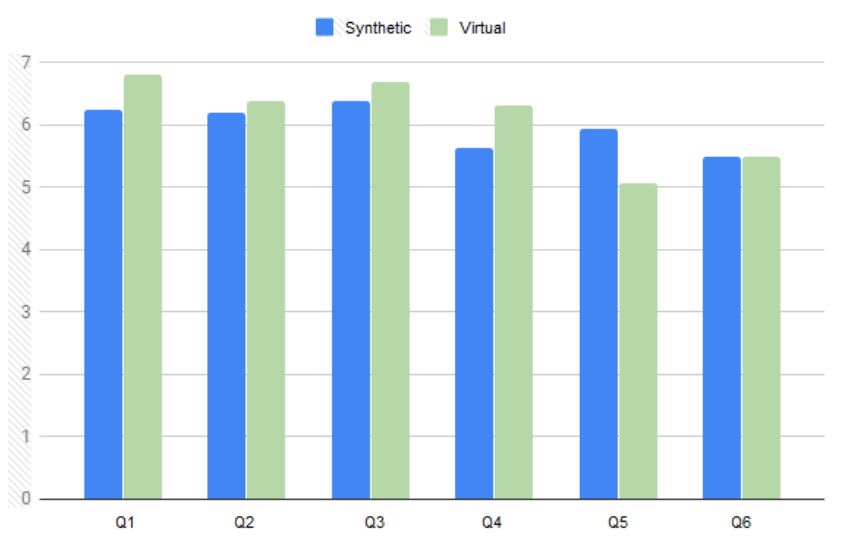

Figure 9. Mean of the SUS presence questions.

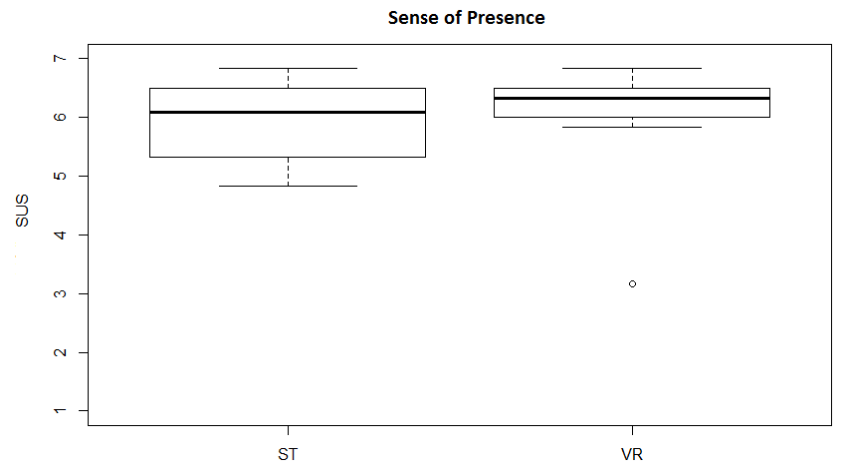

Figure 10. SUS Box Plot using the synthetic brain (ST) and using the virtual brain (VR). The bold lines are the medians and the boxes are interquartile bands with the result.

Concerning encephalon assembly ease, as illustrated in Fig. 11, there was a split of opinion among the participants, especially in the case of the synthetic encephalon, in which exactly half of the people agreed that it was easy to assemble, while the another half disagreed. Regarding the virtual encephalon, a significant group, 6 of the 16 participants, agreed that it was easy to assemble, being that the most of the subjects disagreed. This result is probably associated with little experience in virtual reality, reported by most of the people who participated in the experiment, 7 of whom had never used it before and 5 used it only once.

Regarding the fun, participants also responded to a 5-point Likert scale, related to the affirmative sentence "It was fun to assemble the encephalon". According to the Fig. 12, it is clear that the method, whether virtual or synthetic, was considered fun by the subjects. In spite of this, the results indicate that the use of virtual reality was even more fun than the assembly of the synthetic parts, being that, in this condition, 10 subjects fully agreed and 6 agreed, whereas in the synthetic condition, 5 fully agreed and 11 agreed.

In order to evaluate if the virtual condition could cause cybersickness, the affirmative sentence "The assembly of the encephalon caused discomfort" was presented to the participants. The subjects also responded to a 5-point Likert

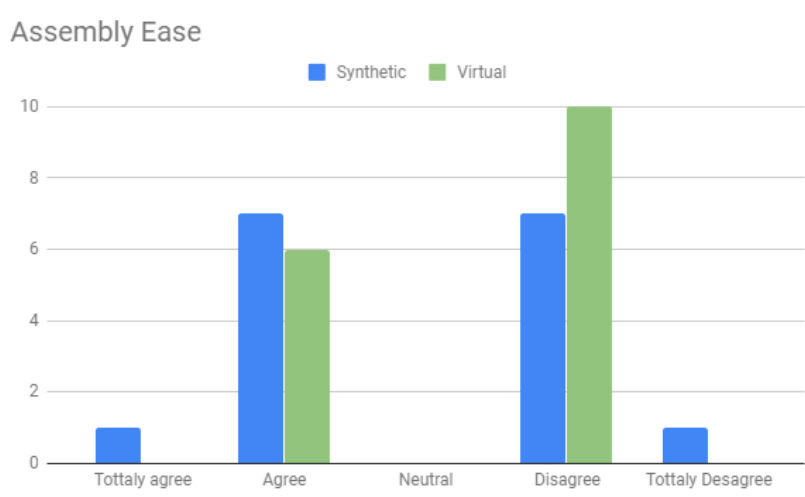

Figure 11. Virtual and synthetic assembly ease.

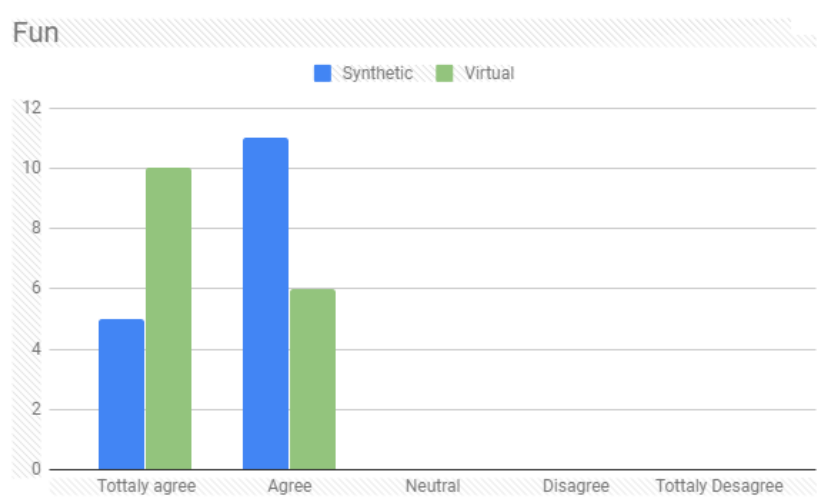

Figure 12. Participants' opinion on the fun in the virtual and synthetic encephalon assembly.

scale with the options "totally disagree", "disagree", "neutral", "agree" and "totally agree". The Fig. 13 shows the results of the participants' answers, with the majority disagreeing both in the synthetic and virtual conditions, with slightly more disagreement in the virtual condition, which suggests that the game is applicable without depletion for the players.

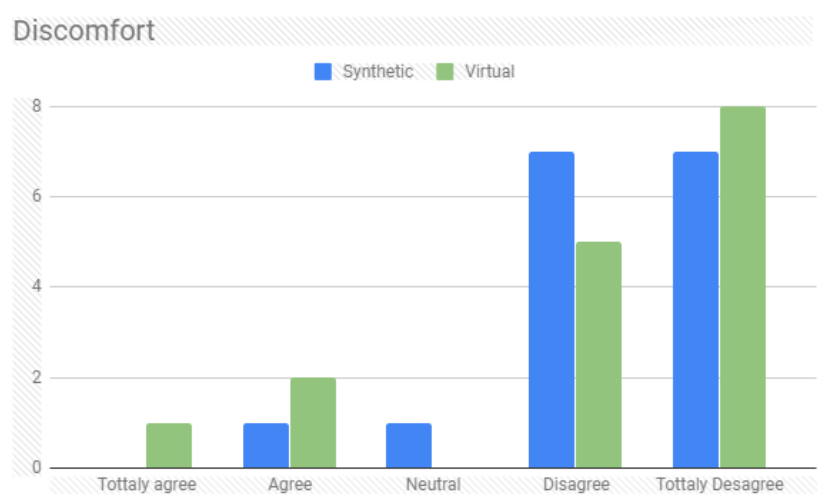

Figure 13. Participants' opinion on the discomfort in the encephalon assembly.

To verify the usefulness for neuroanatomy learning, in the participants' subjective opinion, the affirmative sentence "The assembly of the human brain was useful for my neuroanatomy learning" was presented. As shown in Fig. 14, the vast majority of subjects fully agreed or agreed to the claim, while none of them disagreed and only two considered themselves neutral. This opinion was confirmed by the significant difference found between the performance of the participants in the knowledge test applied before $(M=20.38)$ and after the 
experiment $(\mathrm{C} 1 \mathrm{M}=46.3$ and $\mathrm{C} 2 \mathrm{M}=47.1)$, with no significant difference $(\mathrm{t}$-test $\mathrm{p}=0.9572$ ) between the experimental conditions (Fig. 15).

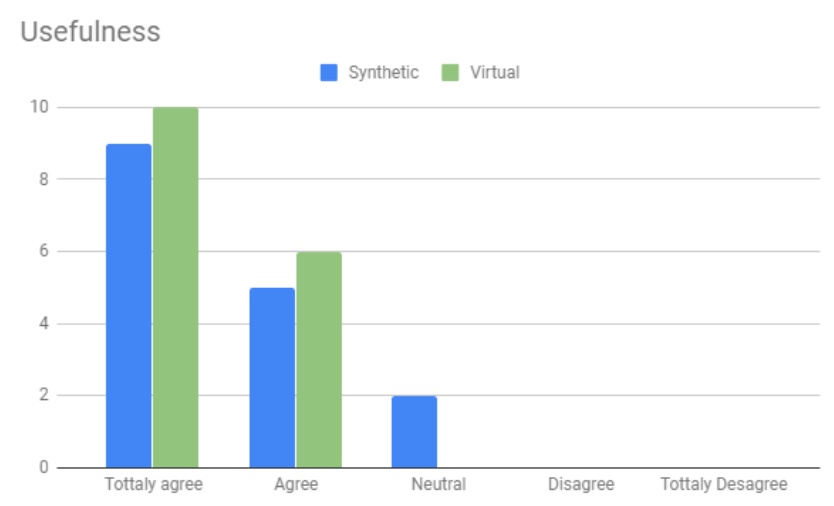

Figure 14. Participants' opinion on the assembly of the encephalon for the neuroanatomy learning.

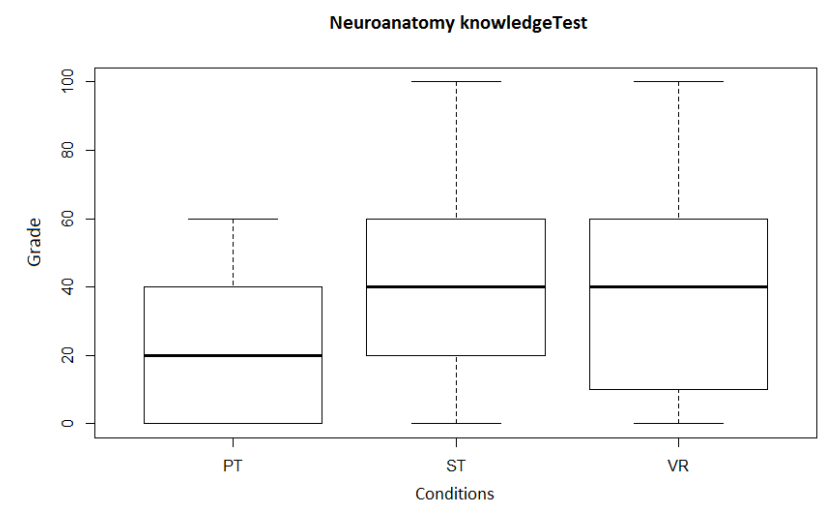

Figure 15. Neuroanatomy knowledge test Box Plot: Pretest (PT), using synthetic brain (ST) and using virtual brain (VR). The bold lines are the medians and the boxes are interquartile bands with the result.

We found no significant difference in ease, utility and discomfort between the assembly of the synthetic and virtual encephalon. Regarding the degree of fun, the participants considered the virtual condition more fun than the synthetic one.

\subsection{Third User Evaluation: Group Learning}

This section presents a formal between-subjects experiment performed to to determine whether or not VR is a suitable platform for group learning d. Souza et al. (2020). We wanted to determine if a group knowledge transfer could be triggered in a VR application, and if we could observe an effect on learning between two different immersion levels. This is important for the scalability of the VR group-based learning approach when HMDs are not available to everyone in class. If the learning level is comparable between roles, the approach could be used in large scale, benefiting more people. More specifically, the goals of the study include to understand the relationship between two VR different immersion levels, to determine the presence level of two different immersion levels, to establish the effectiveness of a VR group-based learning application, and to assess the knowledge retention of two VR different immersion levels users.

\subsubsection{Hypotheses}

For this study we formulated three primary hypotheses.

- H1: the use of the virtual brain allows greater learning than the synthetic brain. This hypothesis is inline to the literature that indicate the effectiveness of VR to the educational process of health professionals Kyaw et al. (2019b); Samadbeik et al. (2018).

- H2: in the VR platform, presence is greater to the student $\mathrm{A}$, who is in a more immersive condition provided by the HMD and its interaction controls, than to the student B, who only visualizes the VE by the projector. According to presence literature, there is a direct relation between immersion and presence Nash et al. (2000); Kim (2005); Slater and Usoh (1993).

- H3: there is an effect of the role (student A/student B) on the acquisition of knowledge.

\subsubsection{Design and Conditions}

To investigate the potential of using VR in group learning, we designed a controlled between-subjects experiment with two conditions varying the learning method: synthetic and virtual. In both conditions, student groups are composed of triads, randomly formed, with one in a more immersive condition and two in a less immersive and less interactive condition. The student " $A$ " is the one who assembles the brain and, in the virtual condition, visualizes it on the HMD. The students "B" students observe the assembly and collaborate verbally to the solution, visualizing the scene on the projector in the virtual condition.

The synthetic method (Fig. 16) refers to the technique currently used in the vast majority of neuroanatomy courses, i.e. synthetic brain models (Fig. 17), given the difficulty of delivering to students a real human encephalon for manipulation in anatomy labs, due to its fragility and rapid degradation. Thus, synthetic brain models are made available to students, which can be disassembled and assembled, but wear out and need replacement over time.

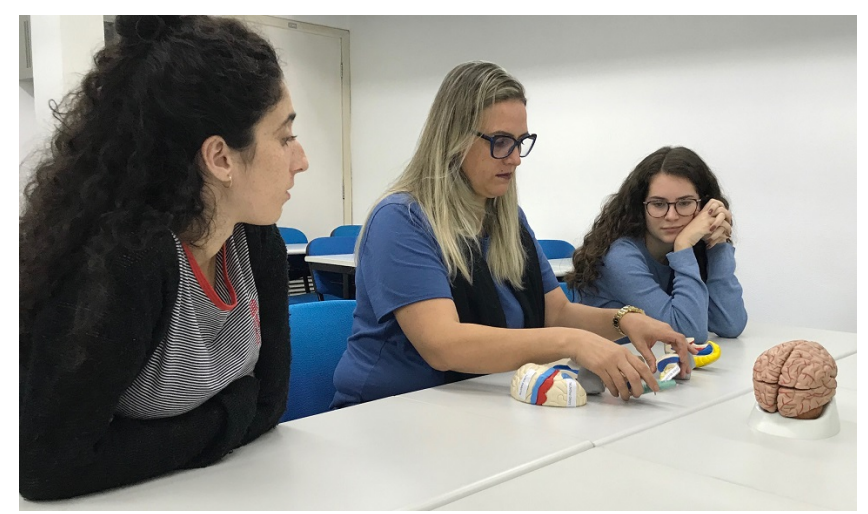

Figure 16. Neuroanatomy students assembling the synthetic human brain. The student in the middle is assembling (student A), while the others are visualizing and verbally collaborating (student B).

The virtual method (Fig. 18) was proposed with the objective of overcoming the learning possibilities of the synthetic method and suppressing the need to acquire numerous units and periodic replacement of these models. As for teaching 
[3B Scientific Brain Model]

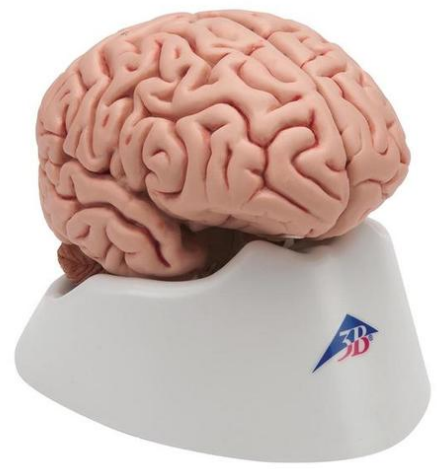

[Giant Functional Center Brain Model]

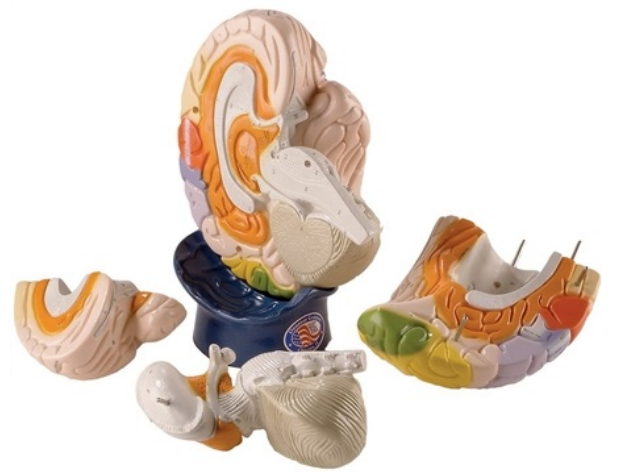

Figure 17. Synthetic brain models examples

and learning processes, in addition to promoting greater engagement, it is possible to include features such as gamification, activating and deactivating support texts and colors, including the names and functions for different brain parts, visualizing the interior parts, including sound effects, among others.

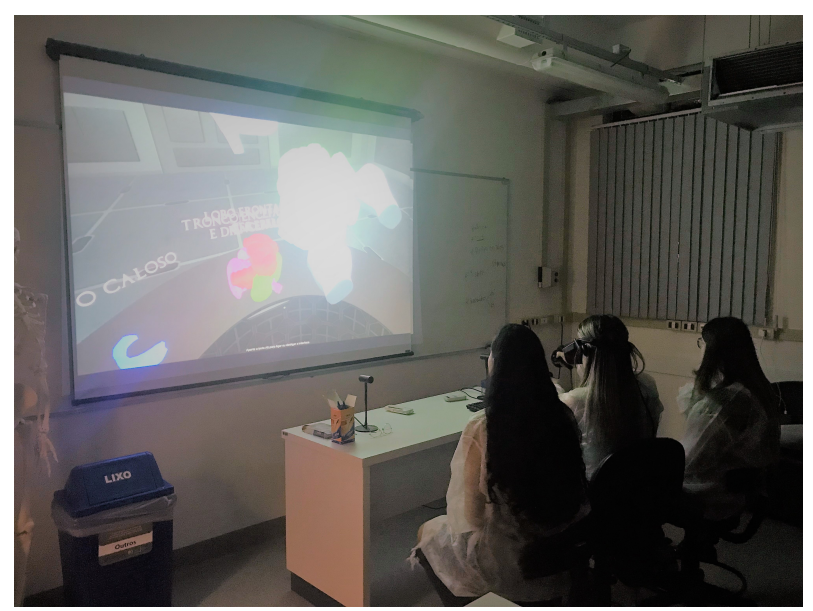

Figure 18. Neuroanatomy students assembling the virtual human brain, with the student in the middle using the HMD (student A) and the others visualizing in the projector and verbally collaborating (student B).

Two types of display are used in the virtual condition: HMD and projection. As illustrated in Fig. 18, in each trio of students, one visualizes the virtual environment through the HMD and the other two simultaneously follow on the projector. Using this combination, it is possible to investigate the benefits and limitations of using group-based VR, with different display techniques simultaneously, which decreases the cost and minimizes the setup time, if compared to the individual immersive VR.

\subsubsection{Participants}

Twenty-three students from a neuroanatomy class participated divided into two groups, randomly formed, to assessment the synthetic and virtual conditions. In each group, the students were organized into teams of three, being that one participant assemble the brain and the other two assist them. We formed seven teams of three students each and one team of two students, totalizing the 23 students sample. As four students, all of B type, being two of the synthetic condition and two of the virtual condition, obtained the maximum score in the pre-knowledge test, their scores were excluded from the sample in order to avoid the ceiling effect in the analysis of learning and retention.

\subsubsection{Metrics}

Objective (knowledge test score) and subjective (presence) measures were used in this study. The performance was obtained in the knowledge test and the subjective measure was collected through the application of a questionnaire. The knowledge test, a beginner neuroanatomy students exam developed by the responsible professor from the University, was composed of a human brain image, with the indication of the six parts that compose it. It was asked of the participants to indicate the name of each part and to the result was assigned a score from zero to 10 points. In order to check the knowledge retention, the same knowledge test developed by the course professor, was applied seven days after the experiment.

To measure presence, the Slater-Usoh-Steed questionnaire Slater et al. (1994), also known as SUS, was used. The SUS questionnaire underwent some changes and currently consists of six items evaluated on a seven-point rating scale, being seven the real sensation of being in a place.

\subsubsection{Task}

In the synthetic condition, the task begins with the eight anatomical parts of the brain, with their respective names, randomly arranged on a table. The main goal of the team is to assemble the synthetic brain in the shortest possible time. To do so, the student A picks up and assembles the parts while their peers only observed and verbally help (Fig. 16).

In the virtual condition, the task also begins with the eight anatomical parts of the brain, with their respective names, randomly arranged on a virtual table. The team goal was the same, i.e. to assemble the virtual brain in the shortest possible time. To do this, the student $\mathrm{A}$ - using HMD for visualization and its controls as virtual hands - picks up and assembles the pieces while their peers visualize by the projector and verbally help (Fig. 18).

\subsubsection{Procedure}

The procedure followed a typical protocol, beginning with a general explanation of the experiment, signing of the consent term and of the image use term, characterization of 
Table 1. Mean and standard deviation for self-assessment, knowledge pretest, knowledge posttest, and retention test. Active are the participants who directly assembled the brain and Passive are those who only observed and collaborated verbally (range scale $0-10$ ).

\begin{tabular}{|c|c|c|c|c|c|}
\hline & \multicolumn{5}{|c|}{ Synthetic } \\
\hline & Group 1 & $\begin{array}{l}\text { Self- } \\
\text { Assessment }\end{array}$ & Pretest & Posttest & Retention \\
\hline All & 10 & $\begin{array}{l}5.13 \\
(1.09)\end{array}$ & $\begin{array}{l}5.50 \\
(2.82)\end{array}$ & $\begin{array}{l}7.66 \\
(2.51)\end{array}$ & $\begin{array}{l}6.66 \\
(3.12)\end{array}$ \\
\hline Active & 4 & $\begin{array}{l}5.20 \\
(0.40)\end{array}$ & $\begin{array}{l}6.67 \\
(1.65)\end{array}$ & $\begin{array}{l}7.92 \\
(2.49)\end{array}$ & $\begin{array}{l}7.50 \\
(2.89)\end{array}$ \\
\hline \multirow[t]{2}{*}{ Passive } & 6 & $\begin{array}{l}5.08 \\
(1.43)\end{array}$ & $\begin{array}{l}4.34 \\
(3.44) \\
\end{array}$ & $\begin{array}{l}7.48 \\
(2.74)\end{array}$ & $\begin{array}{l}6.10 \\
(3.41)\end{array}$ \\
\hline & Group 2 & $\begin{array}{l}\text { Self- } \\
\text { Assessment }\end{array}$ & $\begin{array}{l}\text { Virtual } \\
\text { Pretest }\end{array}$ & Posttest & Retention \\
\hline All & 9 & $\begin{array}{l}5.50 \\
(1.37)\end{array}$ & $\begin{array}{l}4.64 \\
(3.30)\end{array}$ & $\begin{array}{l}8.16 \\
(2.80)\end{array}$ & $\begin{array}{l}8.52 \\
(1.53)\end{array}$ \\
\hline Active & 4 & $\begin{array}{l}5.63 \\
(1.80)\end{array}$ & $\begin{array}{l}2.52 \\
(2.90)\end{array}$ & $\begin{array}{l}7.10 \\
(3.92)\end{array}$ & $\begin{array}{l}7.93 \\
(1.58)\end{array}$ \\
\hline Passive & 5 & $\begin{array}{l}5.40 \\
(1.14)\end{array}$ & $\begin{array}{l}6.34 \\
(2.71) \\
\end{array}$ & $\begin{array}{l}9.00 \\
(1.48)\end{array}$ & $\begin{array}{l}9.00 \\
(1.48)\end{array}$ \\
\hline
\end{tabular}

the participants and neuroanatomy's knowledge pretest application. Subsequently, each group of participants, randomly formed, performed the assembly of the synthetic (Fig. 16) or virtual (Fig. 18) encephalon. After the brain assembly, the participants answered the presence questionnaire and made the neuroanatomy knowledge posttest. In addition, the neuroanatomy knowledge test was reapplied 7 days after the experiment. At no time the participants were aware of the score obtained in the knowledge test, over the different stages of the assessment protocol.

\subsubsection{Results}

For each of the sample distributions collected in this study, we performed a Shapiro-Wilk normality test. When the normal distribution was verified, the t-test was performed and when not, given that the samples are independent, we proceeded with the Mann-Whitney test - an unilateral nonparametric test. The confidence interval was $95 \%$ for statistical significance.

Table 1 shows the results for self-assessment, knowledge pretest, knowledge posttest, and retention test for all participants by role. Knowledge test scores range from zero to ten.

Fig. 19 shows the knowledge test box plot. We see that, for both the synthetic and virtual conditions, students showed an increase in the knowledge test medians (posttest and retention) compared with the medians obtained in the knowledge pretest. This suggests that both methods - synthetic and virtual - are effective in supporting the teaching and learning process of neuroanatomy. Despite the higher median posttest and retention test scores in the virtual condition, there is no statistical evidence (Mann-Whitney test) to state that the use of the virtual brain allows greater learning than the synthetic brain (posttest: $\mathrm{W}=49.5, \mathrm{p}=0.4501$; retention: $\mathrm{W}=48, \mathrm{p}=$ 0.2558 ). However, when comparing the knowledge test performance before and immediately after the experiment, we found statistical significance only in the virtual condition $(p$ $=0.02741$ ). The same could be observed regarding retention, i.e, the significant difference was observed only for the virtual condition $(\mathrm{p}=0.008197)$.

In Fig. 20, we analyze the posttest knowledge and retention scores for the participants who directly assembled the brain (students A) and those who only observed and col-

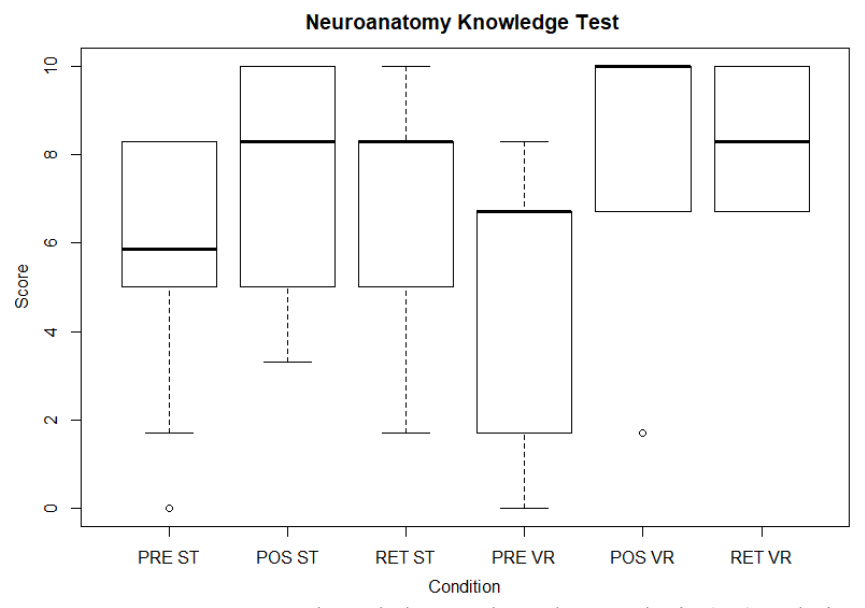

Figure 19. Neuroanatomy knowledge test box plot: synthetic (ST) and virtual (VR) conditions in pretest (PRE), posttest (POS), and retention test (RET). The bold lines are the medians and the boxes are interquartile bands with the result.

laborated verbally (students B). They are also grouped by synthetic and virtual conditions. We can see only small differences between the scores of participants who assembled and those who collaborated, for both conditions. No significant effect was observed in posttest, both in the synthetic $(p=0.825)$ and virtual $(p=0.589)$ conditions. The same occurred for the knowledge retention test, both to the synthetic $(p=0.437)$ and virtual $(p=0.359)$ conditions. Although no difference could be detected due to our small sample size, this could indicate that students in both roles learn with a similar trend.

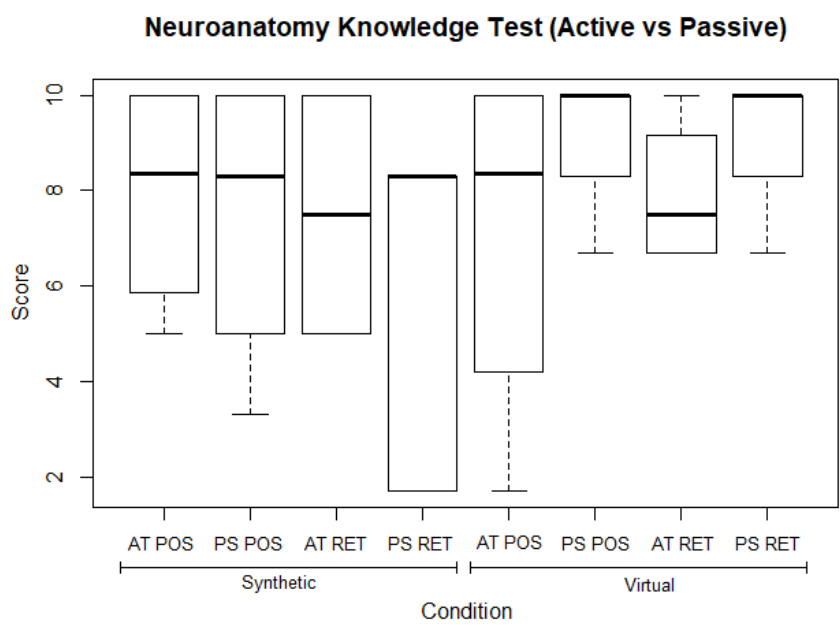

Figure 20. Neuroanatomy knowledge test scores in posttest (POS) and retention test (RET) for student A (AT) and student B (PS) students in the synthetic and virtual conditions. The bold lines are the medians and the boxes are interquartile bands with the result.

From the SUS-presence questionnaire, no statistically significant difference was detected in sense of presence between subjects who assembled and those who collaborate in the virtual condition $(\mathrm{p}=0.413)$. The overall mean for the sense of presence was $5.87(\mathrm{SD}=0.77)$, being $6.17(\mathrm{SD}=0.49)$ among students $\mathrm{A}$ and $5.63(\mathrm{SD}=0.92)$ among students $\mathrm{B}$ (see Fig.21). Again, although no difference was detected in our study due to a small sample, the trend points to a slight lower presence for the passive collaborators. 


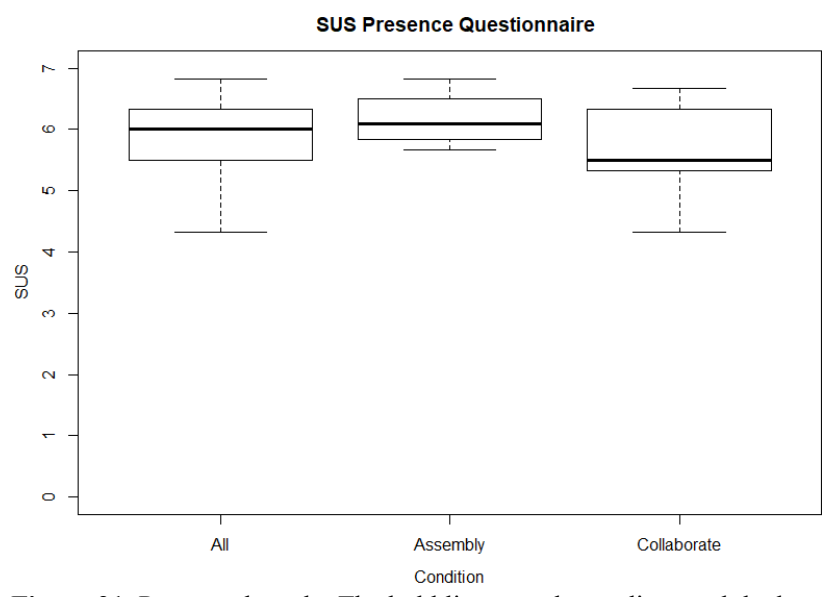

Figure 21. Presence by role. The bold lines are the medians and the boxes are interquartile bands with the results.

\subsubsection{Discussion}

The students' self-assessment is in line with the average pretest score for neuroanatomy knowledge. The scores were relatively low, which is expected from junior undergraduate health students (see Table 1).

When comparing the knowledge test performance before and immediately after the experiment, we found a greater difference in the virtual condition than in the synthetic condition, although the difference is statistically significant only for the virtual condition. The same can be observed regarding retention, i.e, the significant difference was observed only for the virtual condition.

The unconfirmed significance for the synthetic brain occurred probably due the restricted sample size, given that it is the most commonly used neuroanatomy learning method. We hypothesized that using the virtual brain would provide greater learning than the synthetic brain, but despite our hypothesis being inline with the literature that indicate the effectiveness of VR to the educational process of health professionals Kyaw et al. (2019b); Samadbeik et al. (2018), in this study it was not possible to observe significant difference.

A second reason to be investigated is the existence of a possible equivalence between the methods for knowledge transfer, although students often feel more motivated by VR given the immersion, sense of presence and spatial presentation of knowledge Stepan et al. (2017); Kyaw et al. (2019a).

In addition, we hypothesized that learning in VR platform is greater for the students $\mathrm{A}$, who assembles the brain, than for the students B user who only visualizes and verbally collaborates. The experimental results indicated that there is no evidence to affirm that there is any difference in the learning between who assembles and who collaborates, in both synthetic and virtual assembling brain. Extended studies are need to investigate where the expanded use of VR as a teaching tool for simultaneous student groups can benefits all students equally.

We also hypothesized that presence in VR platform is greater to the students $\mathrm{A}$, who is in a more immersive and interactive condition, provided by the HMD and its interaction controls, than to the students $\mathrm{B}$, who only visualizes the VE by the projector. This hypothesis considers the presence literature, which affirm that there is a direct relation between immersion and presence Nash et al. (2000); Kim (2005); Slater
Table 2. Knowledge test mean (standard deviation) scores.

\begin{tabular}{r|c|c}
\hline & Pretest & Posttest \\
\hline Students & $8.5(1.0)$ & $9.0(2.0)$ \\
Lay & $1.5(1.9)$ & $6.0(4.3)$ \\
\hline
\end{tabular}

and Usoh (1993). However, no significant difference was observed in the sense of presence between students A and B. Again, extended studies are need to verify if there is a promising future for the immersive VR use in group-based learning.

Although we did not find any statistically significant results, since we cannot have a larger sample in nowadays Covid-19 pandemic context, the general results are in accordance with the literature, which indicates that the use of VR can play an important role in the learning of different health professionals Samadbeik et al. (2018); Murcia-López and Steed (2018), since the experience is engaging, enjoyable, useful Stepan et al. (2017), and have a positive effect on learning Kyaw et al. (2019b); Samadbeik et al. (2018).

Finally, we need to highlight that our study also has limitations related to the different participants previous knowledge levels for the content addressed. Nevertheless, as Muller Muller Queiroz et al. (2019) states, we believe that the use of educational technologies depends on the needs of the process involved, students profile, and resources available, and so their use is not a decisive factor in the acquisition of knowledge. For further investigation, we suggest a larger sample and the use of the game by people from other areas of knowledge or who are proven to have no previous knowledge on neuroanatomy.

\subsection{Four User Evaluation: Remote Learning}

Given the limitations and opportunities imposed by the ongoing Covid-19 pandemic, we conducted a brief assessment, with eight participants, to explore the possibilities of using the VR serious game in remote education. This study was carried out in a context that restricts the physical presence of students and teachers in educational institutions.

\subsubsection{Participants}

Eight participants performed the remote task, 4 from a neuroanatomy class and 4 lay people. Some lay people participated in the sample, with the aim of also including participants without prior neuroanatomy knowledge. The sample consisted of 2 men and 6 women with an average age of 37.25 (SD 14.25) years. Among the students, all in the junior year of the undergraduate health course, 2 were in biomedicine, 1 in nutrition, and 1 in biomedical engineering. None of the 4 lay participants, all volunteers in this study, were health professionals.

In the self-assessment of knowledge about the human brain anatomy, in a zero to 10 scale, the average among students was 5.62 and among lay people was 0.75 . In the test carried out before the game, the students average score was 8.5 and the lay people mean score was 1.5 (Table 2).

\subsubsection{Procedure}

In this study, the teacher used the Rift CV1 HMD and its touch controls from his home and transmitted the virtual en- 
vironment (VE) through MS Teams, a Web conferencing tool (Fig. 22). The teacher interacted verbally with the students.

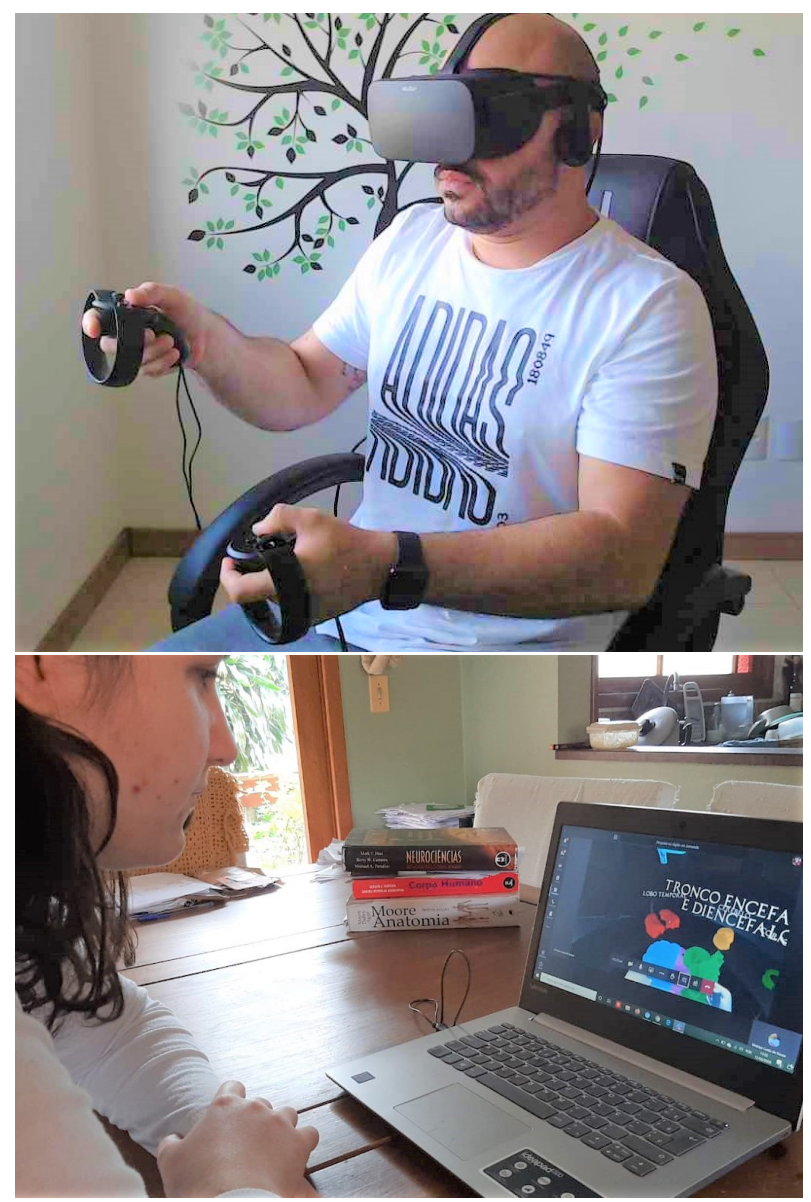

Figure 22. VR remote education setup: teacher operating the game at his home (top); a student guiding the assembly of the virtual brain from her home (bottom).

The teacher acted as an operator, verbally guided by the students who have the challenge of assembling the 3D human brain from its anatomical parts in the shortest possible time. The students visualized the VE (the virtual room with the anatomical brain parts on the table) from the operator advantage point on MS Teams screen, and guided the operator on how to assemble the brain, both using the name of the parts and their colors.

\subsubsection{Results}

The brain assembly mean time was 5.10 minutes (SD 0.12s). At the end of the test, we asked participants three qualitative questions about: the easiness of the game, degree of fun, and usefulness for neuroanatomy learning. They used a scale of 1 to 5 , with 1 the lowest grade and 5 the highest, to respond. For the ease of the game, 6 participants indicated the score 4 and two indicated the score 5. For fun, 2 participants indicated 4 and 6 indicated 5. Equally, 2 indicated 4 and 6 marked 5 for the degree of utility.

We also applied the SUS-presence questionnaires in this study. The results for the 6 questions of the SUS were in average 4.92 , witch is slightly lower than the mean presence registered in the experiment of Section 4.
Among the general comments registered by the participants, some of them stated that the VE dispenses the manipulation of real/synthetic anatomical pieces and, because it is a game, it helps even more in learning. As for the limitations, it was registered that the field of view should be larger, enabling a better visualization of the VE as a whole. One of the participants registered "I felt that I actually participated in the editing, not only gave my opinion" and another "I felt I was in the game".

In the knowledge test applied after the VR game use (Table 2), the mean score from lay persons was 6.0 (being 1.5 in pretest) and from students was 9.0 (being 8.5 in pretest).

Although this pilot study did not include a control group to compare with, the before-after results demonstrate potential for using remote VR as a tool to support teaching and learning processes, especially in the group of participants without prior knowledge on the topic. In addition to the motivation and curiosity instigated by the 3D environment, gamification mobilized and actively engaged the participants, an arguably important factor for learning and retaining knowledge. New tests, in other areas of knowledge and with a larger group of participants are necessary to confirm the indications.

\section{Conclusions and Future Work}

According to the literature, the effective use of VR for health education may improve knowledge transfer and deliver costefficient, safe and effective training. Related works show that immersive serious games are promising, including in health education, when compared to the traditional learning methods, are preferred by users, and improve performance. However, such effects greatly vary with the nature of the task, virtual environment and VR system setup. In addition, collaborative learning has also been considered a method that helps students to retain the information learned.

Our study aimed to advance research on the knowledge transfer and retention in a individual, group-based and remote immersive serious game. Thus, we presented the development and evaluation of an immersive VR serious game to support the neuroanatomy teaching and learning processes in health education. The main objective was to investigate the knowledge transfer and retention, besides presence. To carry out this investigation, we conducted four controlled experiment with 57 participants.

In order to carry out a first assessment with users, the game was used by a group of 10 students. from higher education, who were present in the last class of the Neuroanatomy discipline. The purpose of the evaluation was identify limitations and potentialities of the game, as well as get suggestions that might contribute to future releases. After completing the game, each subject answered a questionnaire, with open and closed questions, for evaluation of experience. Through a Likert scale of 5 points, the participants opined on the ease of use, fun, usefulness and possible discomfort caused by virtual reality. Already on a 7-point scale, each participant answered 6 questions from the SUS questionnaire about the feeling of presence in the game. Additionally, the participants recorded their perceptions of the potentials and game limitations on open-ended questions. All matches were 
recorded for later analysis of behavior. As for the results, the game was considered easy to use $(M=4.0)$, even though most participants have no previous experience with VR, and potentially useful $(\mathrm{M}=4.3)$ for the teaching and learning process of neuroanatomy. Also, the game was considered fun $(M=4.7)$ and did not cause discomfort $(\mathrm{M}=1.9)$, commonly known as cybersickness in VR. Ease of use is potentially associated with the intuitive and natural way of picking up and dropping parts, provided by the use of the Oculus Touch controls, which control the virtual hands. The fun, on the other hand, is possibly associated with the immersive experience provided by the Oculus Rift and the fact of learning by playing.

In the second study, a within-subjects experiment involving 16 participants was conducted with the aim of evaluate the presence and learning between two different test conditions, that is, the assembly of the human encephalon with synthetic and virtual parts, individually performed by the participants. This experiment compared the most common current learning method, based on the use of a synthetic human encephalon, with a proposed virtual version, that intend to motivate the students trough the immersive serious game characteristics. The results of this experiment suggest that the game created is easy to use, even by subjects that are inexperienced in VR, and is potentially useful for teaching and learning processes. In addition, the game was considered fun and did not cause discomfort, which is common in many RV applications. Considering the results of the questionnaire on the feeling of presence, a high average was obtained (6.13), and for four of the six questions, averages above 6.3 were obtained (on a scale of 1 to 7 , with 7 representing the real sensation of being present in a certain place). In the knowledge test, we found a significant difference between the performance before $(M=20.38)$ and after the experiment $(M=46.3$ in condition $\mathrm{C} 1$ and $\mathrm{M}=47.1$ in $\mathrm{C} 2$ ), what indicates that the methods really contributes to the learning process.

In the third experiment we investigated knowledge transfer in a group-based learning condition use of the VR Neuro Game. To do this, a between-subjects experiment was conducted with 23 students to jointly assess learning, knowledge retention, and sense of presence. As a control condition, grouped students assembled a physical model of the human brain, while in the experimental condition, a virtual brain was assembled. In each group, one participant assembled the brain, while the others observed and verbally collaborated in a group-based learning strategy. Results shown high mean scores in the virtual condition. When comparing the knowledge test performance before and immediately after the experiment, we found significant difference only for the virtual condition. The same can be observed for retention.

Given the limitations imposed by the current reality of the Covid-19 pandemic to get a bigger sample, we conducted a fourth user study with eight participants to explore the possibilities of the VR serious game use in the remote education context. The results demonstrate good potential for using remote VR as a tool to support teaching and learning processes, especially in the group without prior knowledge on the topic.

Although we did not identify a significant difference in knowledge and retention, as well as in presence, the general results suggest the possibility of expanded use of immersive VR resources, applied to group learning, offering large-scale economic training, and effective when compared to individual immersive VR.

Future research, with a larger sample and different knowledge objectives, is necessary to better determine whether immersive VR is an adequate platform for group learning, as well as for the different immersion levels students.

\section{References}

Ananiadou, K. and Claro, M. (2009). 21st century skills and competences for new millennium learners in oecd countries. (41).

Billinghurst, M. and Duenser, A. (2012). Augmented reality in the classroom. Computer, 45(7):56-63.

Bond, M., Marín, V., Dolch, C., Bedenlier, S., and ZawackiRichter, O. (2018). Digital transformation in german higher education: student and teacher perceptions and usage of digital media. International Journal of Educational Technology in Higher Education, 15.

Car, J., Carlstedt-Duke, J., Tudor Car, L., Posadzki, P., Whiting, P., Zary, N., Atun, R., Majeed, A., and Campbell, J. (2019). Digital education in health professions: The need for overarching evidence synthesis. J Med Internet Res, 21(2):e12913.

Cerf, V. G. (2020). Implications of the covid-19 pandemic. Commun. ACM, 63(6):7.

Chittaro, L. and Buttussi, F. (2015). Assessing knowledge retention of an immersive serious game vs. a traditional education method in aviation safety. IEEE Transactions on Visualization and Computer Graphics, 21(4):529-538.

Crisp, N., Gawanas, B., and Sharp, I. (2008). Training the health workforce: scaling up, saving lives. The Lancet, 371(9613).

d. Souza, V. C., Nedel, L., Kopper, R., Maciel, A., Loges, K., and Schelemmer, E. (2020). The effect of virtual reality on knowledge transfer and retention in colla-borative groupbased learning for neuroanatomy students. In $202022 \mathrm{th}$ Symposium on Virtual and Augmented Reality (SVR).

Dias, R. d. O. and Kastrup, V. (2013). Skills society and cognition policies in the formation of teachers. Paidéia, 23(55):243-251.

Donovan, T. (2010). Replay: The History of Video Games. Yellow Ant.

Hvolbek, A., Nilsson, P., Sanguedolce, F., and Lund, L. (2019). A prospective study of the effect of video games on robotic surgery skills using the high-fidelity virtual reality robotix simulator. Advances in Medical Education and Practice, Volume 10:627-634.

Jou, M. and Wang, J. (2013). Investigation of effects of virtual reality environments on learning performance of technical skills. Computers in Human Behavior, 29(2). Advanced Human-Computer Interaction.

KenResearch (2018). Global Digital Gaming Market (20182023). Netscribes.

Kim, G. J. (2005). Designing virtual reality systems - the structured approach. Springer.

Kockro, R., Amaxopoulou, C., Killeen, T., Wagner, W., Reisch, R., Gutenberg, A., Giese, A., Stofft, E., and Stadie, 
A. (2015). Stereoscopic neuroanatomy lectures using a three-dimensional virtual reality environment. Annals of Anatomy - Anatomischer Anzeiger.

Kruglikova, I., Grantcharov, T., Drewes, A., and FunchJensen, P. (2009). The impact of constructive feedback on training in gastrointestinal endoscopy using high-fidelity virtual-reality simulation: a randomised controlled trial. Gut, 59:181-5.

Kyaw, B. M., Saxena, N., Posadzki, P., Vseteckova, J., Nikolaou, C. K., George, P. P., Divakar, U., Masiello, I., Kononowicz, A. A., Zary, N., and Tudor Car, L. (2019a). Virtual reality for health professions education: Systematic review and meta-analysis by the digital health education collaboration. J Med Internet Res, 21(1):e12959.

Kyaw, B. M., Saxena, N., Posadzki, P., Vseteckova, J., Nikolaou, C. K., George, P. P., Divakar, U., Masiello, I., Kononowicz, A. A., Zary, N., and Tudor Car, L. (2019b). Virtual reality for health professions education: Systematic review and meta-analysis by the digital health education collaboration.

Maturana, H. and Varela, F. (1987). The tree of knowledge: the biological roots of human understanding. New Science Library. Shambhala.

Maturana, H. R. (1990). Science and Daily Life: The Ontology of Scientific Explanations, pages 12-35. Springer Netherlands, Dordrecht.

Menin, A., Torchelsen, R., and Nedel, L. (2018). An analysis of vr technology used in immersive simulations with a serious game perspective. IEEE Computer Graphics and Applications, 38:57-73.

Michael, D. R. and Chen, S. L. (2005). Serious Games: Games That Educate, Train, and Inform. Muska Lipman/Premier-Trade.

Muller Queiroz, A. C., Nascimento, A., Tori, R., and da Silva Leme, M. (2019). Immersive Virtual Environments and Learning Assessments, pages 172-181.

Murcia-López, M. and Steed, A. (2018). A comparison of virtual and physical training transfer of bimanual assembly tasks. IEEE Transactions on Visualization and Computer Graphics, 24(4).

Nash, E. B., Edwards, G. W., Thompson, J. A., and Barfield, W. (2000). A Review of Presence and Performance in Virtual Environments. International Journal of HumanComputer Interaction, 12(1).

Nedel, L., De Souza, V. C., Menin, A., Sebben, L., Oliveira, J., Faria, F., and Maciel, A. (2016). Using Immersive Virtual Reality to Reduce Work Accidents in Developing Countries. IEEE Computer Graphics and Applications, 36(2):36-46.

Oberdörfer, S. and Latoschik, M. E. (2016). Interactive gamified 3d-training of affine transformations. In Proceedings of the 22Nd ACM Conference on Virtual Reality Software and Technology, VRST '16, pages 343-344, New York, NY, USA. ACM.

Oliver, B. and de St Jorre, T. J. (2018). Graduate attributes for 2020 and beyond: recommendations for australian higher education providers. Higher Education Research \& Development, 37(4).

Panchaphongsaphak, B., Burgkart, R., and Riener, R. (2005).
Braintrain: Brain simulator for medical vr application. Studies in health technology and informatics, 111:378-84. Papert, S. (1993). The Children's Machine: Rethinking School in the Age of the Computer. Basic Books, Inc., New York, NY, USA.

Rachevsky, D., Costa de Souza, V., and Nedel, L. (2018). Visualization and interaction in immersive virtual reality games: a user evaluation study.

Samadbeik, M., Yaaghobi, D., Bastani, P., Abhari, S., Rezaee, R., and Garavand, A. (2018). The applications of virtual reality technology in medical groups teaching. Journal of Advances in Medical Education amp; Professionalism, 6(3):123-129.

Schuemie, M. J., Van der Straaten, P., Krijn, M., and Van der Mast, C. (2001). Research on Presence in VR : a Survey. CyberPsychology and Behavior, 4(2):183-201.

Silverstein, J., Dech, F., Edison, M., Jurek, P., Helton, w., and Espat, N. (2002). Virtual reality: Immersive hepatic surgery educational environment. Surgery, 132:274-7.

Sjölie, D. (2013). Human brains and virtual realities: Computer-generated presence in theory and practice.

Slater, M. (2004). How Colorful Was Your Day? Why Questionnaires Cannot Assess Presence in Virtual Environments. Presence Teleoperators and Virtual Environments, 13(4):484-493.

Slater, M. (2014). Grand Challenges in Virtual Environments. Frontiers in Robotics and AI, 1:3.

Slater, M. and Steed, A. (2000). A Virtual Presence Counter. Presence: Teleoperators and Virtual Environments, 9(5).

Slater, M. and Usoh, M. (1993). Presence in immersive virtual environments. In IEEE Virtual Reality Annual International Symposium.

Slater, M., Usoh, M., and Steed, A. (1994). Depth of Presence in Virtual Environments. Presence: Teleoperators and Virtual Environments, 3(2):130-144.

Slater, M., Usoh, M., and Steed, A. (1995). Taking steps: The influence of a walking technique on presence in virtual reality. ACM Trans. Comput.-Hum. Interact., 2(3):201-219.

Souza, V., Nedel, L., Loges, K., and Schlemmer, E. (2019). Development and evaluation of a immersive serious game to support neuroanatomy teaching and learning. In $S B C$ Proceedings of SBGames 2019.

Souza, V., Rachevsky, D., Nedel, L., Loges, K., Schlemmer, E., and Costa de Souza, V. (2018). Demo: A virtual reality game for neuroanatomy teaching and learning.

Stepan, K., Zeiger, J., Hanchuk, S., Del Signore, A., Shrivastava, R., Govindaraj, S., and Iloreta, A. (2017). Immersive virtual reality as a teaching tool for neuroanatomy: Immersive vr as a neuroanatomy teaching tool. International Forum of Allergy Rhinology, 7.

Usoh, M., Catena, E., Arman, S., and Slater, M. (2000). Using presence questionnaires in reality. Presence: Teleoperators and Virtual Environments, pages 1-16.

Wiberg, M., Taylor, A., and Rosner, D. (2020). Responding to the covid-19 pandemic: An invitation. Interactions, 27(3):5.

Yusoff, A., Crowder, R., Gilbert, L., and Wills, G. (2009). A conceptual framework for serious games. In 2009 Ninth 
IEEE International Conference on Advanced Learning Technologies, pages 21-23.

Zhang, M., Zhang, Z., Chang, Y., Aziz, E., Esche, S., and Chassapis, C. (2018). Recent developments in gamebased virtual reality educational laboratories using the microsoft kinect. International Journal of Emerging Technologies in Learning (iJET), 13:138. 